\title{
Outgassing from Open and Closed Magma Foams
}

\begin{abstract}
Felix W. von Aulock ${ }^{1 *}$, Ben M. Kennedy ${ }^{2}$, Anton Maksimenko ${ }^{3}$, Fabian B. Wadsworth ${ }^{4}$ and Yan Lavallée ${ }^{1}$

${ }^{1}$ School of Environmental Sciences, University of Liverpool, Liverpool, United Kingdom, ${ }^{2}$ Geological Sciences, University of Canterbury, Christchurch, New Zealand, ${ }^{3}$ Imaging and Medical Beamline, Australian Synchrotron, Clayton, VIC, Australia, ${ }^{4}$ Section for Mineralogy, Petrology and Geochemistry, Department of Earth and Environmental Sciences, Ludwig-Maximilian University of Munich, Munich, Germany
\end{abstract}

During magma ascent, bubbles nucleate, grow, coalesce, and form a variably permeable porous network. The reorganization, failing and sealing of bubble walls may contribute to the opening and closing of the volcanic system. In this contribution we cause obsidian to nucleate and grow bubbles to high gas volume fraction at atmospheric pressure by heating samples to $950^{\circ} \mathrm{C}$ for different times and we image the growth through a furnace. Following the experiment, we imaged the internal pore structure of selected samples in $3 \mathrm{D}$ and then dissected for analysis of textures and dissolved water content remnant in the glass. We demonstrate that in these high viscosity systems, during foaming and subsequent foam-maturation, bubbles near a free surface resorb via diffusion to produce an impermeable skin of melt around a foam. The skin thickens non-linearly through time. The water concentrations at the outer and inner skin margins reflect the solubility of water in the melt at the partial pressure of water in atmospheric and water-rich bubble conditions, respectively. In this regime, mass transfer of water out of the system is diffusion limited and the sample shrinks slowly. In a second set of experiments in which we polished off the skin of the foamed samples and placed them back in the furnace to allow open system outgassing, we observe rapid sample contraction and collapse of the connected pore network under surface tension as the system efficiently outgasses. In this regime, mass transfer of water is permeability limited. We conclude that diffusion-driven skin formation can efficiently seal connectivity in foams. When rupture of melt film around gas bubbles (i.e., skin removal) occurs, then rapid outgassing and consequent foam collapse modulate gas pressurization in the vesiculated magma. The mechanisms described here are relevant to the evolution of pore network heterogeneity in permeable magmas.

Keywords: degassing, outgassing, foam, bubbles, skin, permeability, porosity

\section{INTRODUCTION}

During ascent and eruption, magma vesiculates due to changes in pressure and temperature (e.g., Zhang, 1999). This vesiculation is initiated by the oversaturation of volatile components that exsolve through the nucleation and growth of bubbles, which may produce a magmatic foam (Sparks, 1978). The development of porosity is central to the volcanic eruptions as it controls the buoyancy of magma (Gonnermann and Manga, 2007), its rheology (Llewellin et al., 2002) and the pore pressure (Martel et al., 2000) that influence eruptive behavior. During vesiculation, bubbles 
may coalesce and create a variably permeable network that regulates outgassing (Lindoo et al., 2016), which if efficient may result in foam collapse. If outgassing (i.e., the removal of volatiles from the system) is prevented by a low permeability network or barrier (Yoshimura and Nakamura, 2008), pressure may build up and the strain rate at the bubble walls may exceed the inverse of the relaxation time of the melt phase, in which case magma fragments, potentially triggering an explosive eruption (Dingwell, 1996). Collapse of the bubble network is driven by stress (Ashwell et al., 2015), and/or shear (Okumura et al., 2008, 2009) and surface tension (Kennedy et al., 2016). This densification may lead to the formation of a less permeable magmatic conduit fill that can plug the volcanic system leading to an overpressurization (Michaut et al., 2009; Ashwell et al., 2015).

Numerical models and laboratory measurements have contributed to our understanding of porosity evolution in magma (Navon and Lyakhovsky, 1998; Blower, 2001). Recent developments in 3D imaging of the foaming process in situ as well as computational simulation of fluid flow through those pores have constrained the development of permeable networks in magma (e.g., Baker et al., 2012). However, theoretical models of bubble growth are difficult to reconcile with observations of natural erupted products (e.g., Rust and Cashman, 2011). Geochemical (volatile) and textural heterogeneities of eruptive products highlight the complexity of outgassing behavior in silicic volcanic conduits (e.g., Castro et al., 2012, 2014). And yet, our current understanding fails to capture the complex physical and chemical interplay taking place during magma degassing and outgassing. Local changes in pore network geometry and the development of short-lengthscale heterogeneity can preclude or localize outgassing; processes ubiquitous in natural volcanic interiors (e.g., Stasiuk et al., 1996; Kendrick et al., 2013; Farquharson et al., 2016). Fragmentation can open pathways for outgassing that might subsequently heal (Tuffen et al., 2003; Cabrera et al., 2010). Previous work has focussed on the growth of bubbles in homogeneous foams and the resultant connectivity (Pistone et al., 2015; Lindoo et al., 2016), or on the disruption of foams during shearing (Okumura et al., 2009).

Here, we experimentally test the evolution of foams during either diffusive (closed foam) or capillary-forced (open foam) outgassing, and discuss the development of degassing and outgassing processes in closed and open systems. Vesiculation in natural obsidian samples is achieved through temperature increase causing oversaturation of volatiles in the silicate melt. These experiments allow us to explore the impact of pore network heterogeneity on the outgassing processes in volcanic settings.

\section{MATERIALS AND METHODS}

We used homogeneous obsidian from Ben Lomond dome in New Zealand. These samples were selected as they contain 0.12-0.16 wt.\% (total) water homogeneously distributed across the sample cores (von Aulock, 2013). This concentration exceeds the solubility of water in calc-alkaline rhyolite at atmospheric pressure (0.1 MPa) and $950^{\circ} \mathrm{C}$ Liu et al. (2005). The samples are crystal-poor $(<1$ vol.\% in minor flow bands) and contain no significant macroscopic or microscopic porosity (see Supplementary Figure S1). The location, chemistry and rheological properties of similar samples is described by Stevenson et al. (1993, 2001) as BL-6 (gray obsidian). These analyses match our observations. Only specimen without macroscopically visible heterogeneities, such as spherulites or other crystals were selected for the experiments. A scanning electron microscopy image of a representative sample of the starting material can be found in the Supplementary Material.

We heated 7 cylindrical cores $(9.7 \mathrm{~mm}$ diameter and $10 \mathrm{~mm}$ length) to $950^{\circ} \mathrm{C}$ at $10^{\circ} \mathrm{C} \mathrm{min}^{-1}$ and kept them at isothermal dwells of 5-120 h. The samples (BL-5-120) were then removed from the furnace and quenched in air to room temperature and cut radially for textural and geochemical analyses.

To measure the thickness of the outer layer of glass that developed at the sample edge (see results), we filled the pores exposed on both halves of the dissected foams with white acrylic paint before polishing the dissected surface to improve the contrast between the pores (white) and glass (black) for imaging. The skin area was delimited manually and, for consistency, we neglected any areas containing bubbles. The thickness of these skins was then measured based on Euclidean distances using the Bonej package in ImageJ (Doube et al., 2010). Here we report the mean skin thicknesses of each sample.

The water content of the original (BL) and one foamed sample (BL-FTIR) was measured on the Micro-infrared Analysis beamline of the Australian Synchrotron both on an online Bruker with MCT detector and an offline Focal plane array detector at a $\mathrm{pixel} / \mathrm{spot}$ size of $5 \times 5 \mu \mathrm{m}$ and pixel distance of $3 \mu \mathrm{m}$. These data were complemented by conventional FTIR measurements at the University of Liverpool at spot sizes of $\sim 100 \times 100 \mu \mathrm{m}$. Samples were first cut and doubly polished to thick sections of $\sim 100-500$ $\mu \mathrm{m}$ and their absorption at the $\mathrm{OH}^{-}$vibrational band at 3,760 $\mathrm{cm}^{-1}$ analyzed. The data were analyzed using a constant density of $2,216 \mathrm{~kg} \mathrm{~m}^{-3}$ (measured by helium pycnometry) an absorption coefficient of 88 (Ihinger et al., 1994) and data were interpreted following von Aulock et al. (2014).

A second set of experiments with two additional sample cores (BL-CT-A and BL-CT-B) was conducted for $24 \mathrm{~h}$ at $950^{\circ} \mathrm{C}$. After the $24 \mathrm{~h}$ the outer edge of one of two foamed samples (BL-CTB) was polished off, exposing the porous core to allow open system outgassing. The pair of samples was placed again in the furnace for $>24 \mathrm{~h}$ hours to monitor the evolution of the foam. While in the furnace, photographs were captured at 1 image per minute through a window. The internal structure of these samples was then reconstructed in $3 \mathrm{D}$ using micro X-ray computed tomography (XCT).

The evolution of sample volume was estimated by image analysis. We converted images to greyscales and adjusted contrast and brightness in Adobe Lightroom; we set manual thresholds in ImageJ (Schneider et al., 2012) and manually refined boundaries in Adobe Photoshop CS6 ${ }^{\mathrm{TM}}$. Assuming that the sample could be approximated as cylindrical, we use the timedependent silhouette area $A(t)$ relative to the initial area $A_{i}$ to compute the time-dependent ratio of the sample volume $V(t)$ to the initial known volume $V_{i}$ by the relationship $V(t) / V_{i}=$ $\left(A(t) / A_{i}\right)^{3 / 2}$ (Wadsworth et al., 2016). A table of samples and the applied analysis can be found in the Supplementary Material (Table S1). 


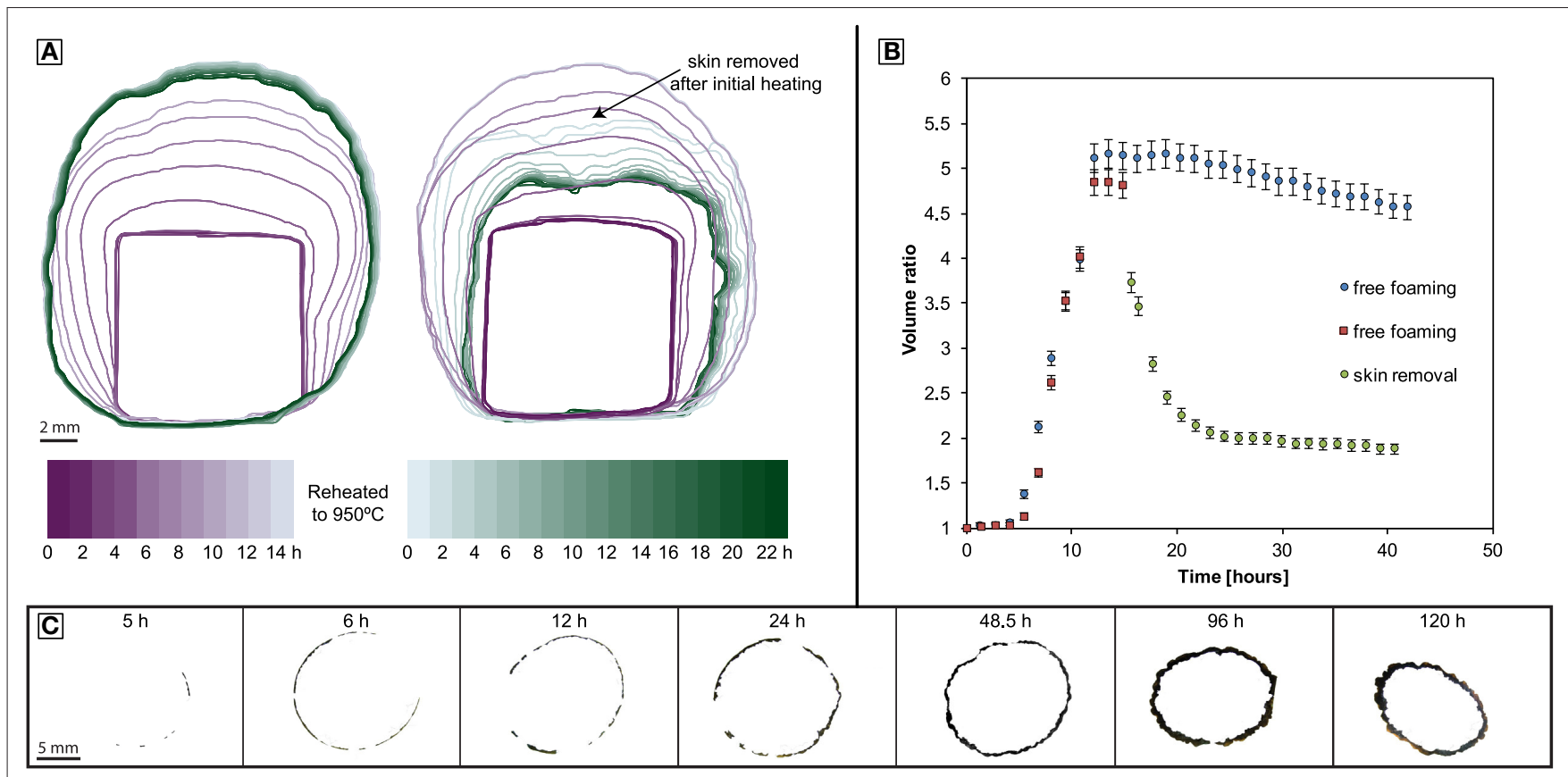

FIGURE 1 | Geometry evolution of foamed experimental samples. (A) Left: Foaming with coincident skin formation. Right: Foaming followed by surface-tension driven collapse after removal of the skin. (B) Tracking the time dependent volume of the samples in (A); both samples are foaming freely until the skin is removed of one of them (sample BL-CT-B, red squares); error bars refer to a minimum estimated error of 3\%. (C) Cross sections of the skin development.

\section{RESULTS}

During the experiments, samples expand rapidly and then deflate slowly while a bubble-free outer layer of liquid thickens. In experiments where this outer layer of liquid is removed, the sample deflates more rapidly, and the final volume approaches the pre-experimental volume (Figure 1). XCT reveals that the volume increase is due to vesiculation (Figure 2). The samples expand by $300-400 \%$ in the first $6-12 \mathrm{~h}$. Beyond $12 \mathrm{~h}$, the foam volume slowly reduces at an apparently constant rate of $\sim 1 \% \mathrm{~h}^{-1}$. In experiments exceeding $5 \mathrm{~h}$, a discernible bubble-free skin develops around the bubbly core. The skin thickens non-linearly through time (Figure 1).

We mapped the water concentration distribution across the thickening skin preserved as a glassy rind on quenching. The analysis shows a very low total water content $(0.04 \mathrm{wt} . \%)$ along the outer margin of the skin and up to $\sim 0.1 \mathrm{wt} . \%$ at the inner margin (Figure 3). The latter value also represents the average water concentration of bubble walls analyzed inside the foam.

The internal structure of the foamed samples was reconstructed in 3D using XCT. The foamed interior is surrounded by a dense, vesicle-free "skin" glass. This skin shows a dimpled surface and no pores or micro-fractures that would connect the inner bubble network to the outside. The lack of connectivity between the inside and the outside of the sample is supported by photomicrographs and by He-pycnometry. The 3D reconstructions show that most vesicles are near-spherical with the exception of the vesicles adjacent to the dense skin, which are oblate and elongate along inner margin of the skin.
The fully foamed samples BL-CT-A and BL-CT-B were removed from the furnace after $24 \mathrm{~h}$ at $950^{\circ} \mathrm{C}$. One of these samples was polished slightly to remove the outermost skin of glass on the surface of the sample; the other sample was left untouched. When reheating the samples to $950^{\circ} \mathrm{C}$ the polished sample collapses quickly (within $8-10 \mathrm{~h}$ ) toward the original dense glass volume (Figures 1, 3). The pore size of these samples was measured using XCT images and the ImageJ particle analyser tool (Schneider et al., 2012) final mean radius of $60 \pm 10 \mu \mathrm{m}$ (with skin using Feret radii) and $25 \mu \mathrm{m}$ (without skin using volume equivalent diameter).

\section{DISCUSSION}

The foaming experiments detailed here demonstrate the strong physical control of a water pressure contrast across a surface on the development, stability and water content of magmatic foams. Due to vesiculation the samples rapidly increase in volume (Figure 1). In the sample interior and after the nucleation phase, bubble growth proceeds according to bubble growth laws (Proussevitch et al., 1993; Navon et al., 1998; Blower et al., 2001). Although the initial material is a natural sample that contains some crystals and heterogeneities, no significant impact of the texture on the foaming behavior could be observed. However, after foaming $>12 \mathrm{~h}$, heterogeneous expansion can be observed (see Figure 1C) that was caused by heterogeneous heating in the furnace. We estimate the temperature to vary within $\pm 3-5^{\circ} \mathrm{C}$ 

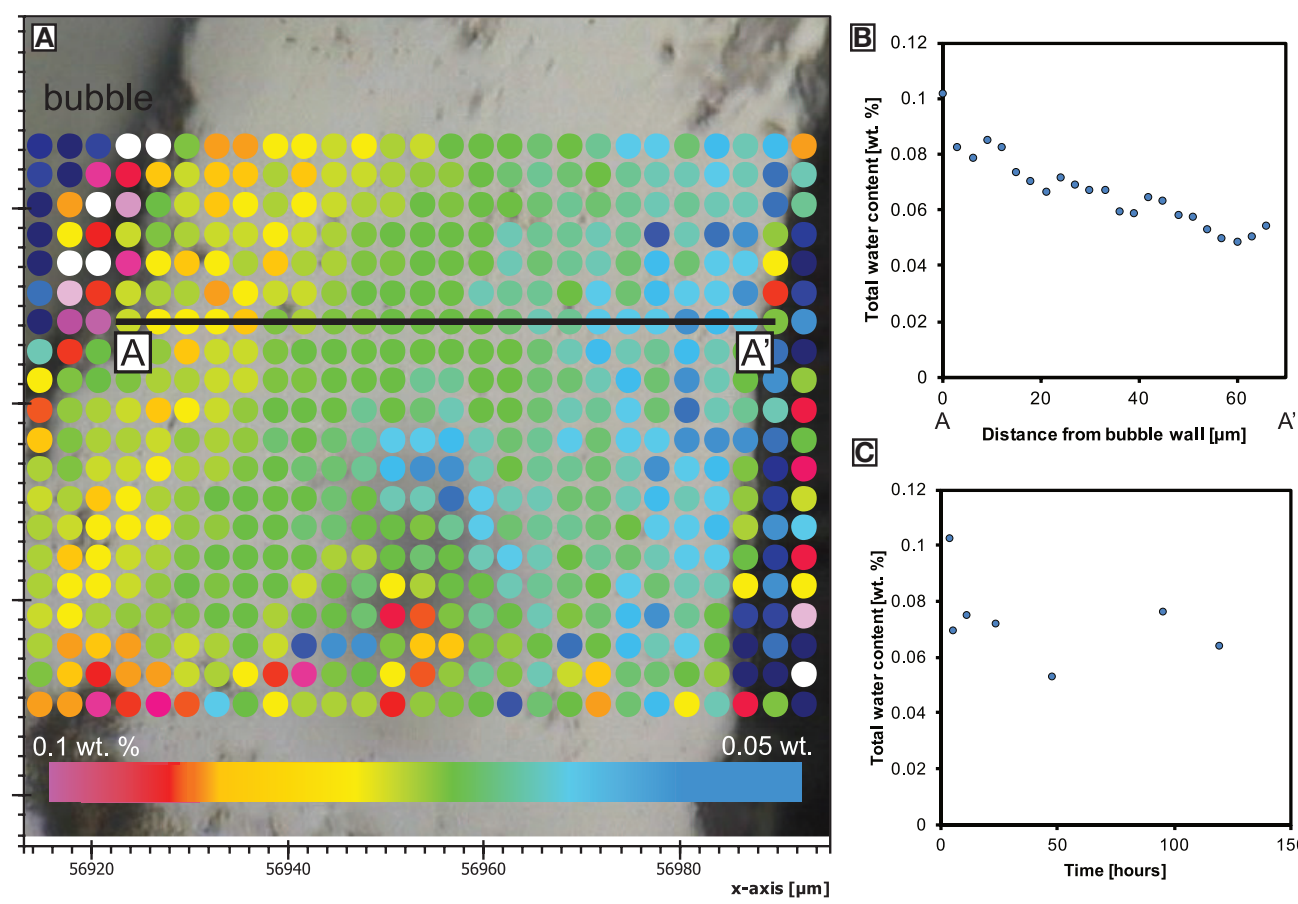

C

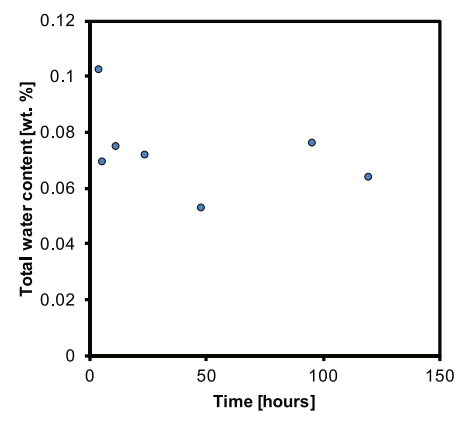

FIGURE 2 | Total water concentration (determined by both synchrotron-source or conventional FTIR) in the skin. (A) Spot locations from a vesicle at the inner skin margin toward the outer skin margin at the sample edge of BL-24 at a minimum thickness of only $60 \mu \mathrm{m}$ (axis labels in $\mu \mathrm{m}$ ). (B) The water concentration profile from (A). (C) The average water concentration over 2-5 measurement points at the inner skin margin during skin formation (error bars indicate standard derivation).

over the diameter of the sample, particularly in experiments that were observed through a window.

The onset of nucleation occurs after a significant delay of up to $5 \mathrm{~h}$ which could be caused by a combination of low initial oversaturation (of only $<0.12$ wt.\% water above the solubility at the experimental temperature) and lack of nucleation sites, such as microlites. The presence of a surface through which a water pressure difference exists, favors diffusion and the development of an outer skin. This has been observed in other samples (Ryan et al., 2015) and is also referred to as bubble-free margin (Yoshimura and Nakamura, 2008). Once the maximum volume is reached when the water in bubble-bubble films has equilibrated, exsolution ceases but bubble coalescence and redistribution can continue internally. In our samples, bubble-bubble contacts have flattened as they have continued to grow after the skin has thickened, degassed and increased in viscosity (Figure 2). The constant water concentration at the interior of the skin through time as well as the apparent mechanical barrier to bubble growth evidences the attainment of a diffusion-controlled, closed-system foam structure. The water concentration from the sample edge records a profile that is increasing toward the sample interior and through the developing skin (Figure 2). This implies that there was a diffusion gradient from the bubble growth region in the sample core toward the sample exterior and we infer that mass transfer of water by diffusion has occurred out of the sample. This is consistent with the different partial pressure of water between the solubility limit at the bubble walls in the sample (using the model of Liu et al., 2005) and the lower solubility at the sample exterior associated with a lower partial pressure of water in air (0.04 wt.\% if experiments started at $30^{\circ} \mathrm{C}$ and $100 \%$ relative humidity). The ongoing process of water diffusion results in bubbles proximal to the sample edge shrinking as water is removed through the melt skin out of the sample. As mass is diffusively removed from the bubbles near to the internal skin margin, they resorb (McIntosh et al., 2014) and surface tension stresses reduce the bubble volume. Therefore, bubbles adjacent to sample edge are progressively consumed by this process and promote the development and thickening of the skin (Figure 1; Yoshimura and Nakamura, 2008).

Consistent with Yoshimura and Nakamura (2008), we show that diffusion controls skin formation and thickening. This is evidenced by the linear scaling between skin thickness and the square root of time (Figure 3 ). This additionally suggests that the skin thickness evolves with the diffusion length $L$ where $L \approx \sqrt{D t}$ and $D$ is a mean of the diffusivity of water in the skin and $t$ is the time. At the experimental conditions and the water concentration range $0.05-0.1 \mathrm{wt}$. $\%, D$ is in the range $2.48 \times 10^{-13}$ to $4.946 \times$ $10^{-13} \mathrm{~m}^{2} \mathrm{~s}^{-1}$ (Zhang and $\mathrm{Ni}, 2010$ ). This relatively tight range justifies use of a mean diffusivity $D$ in our assessment of the diffusion length, while a full analysis would take account of the spatial distribution of diffusivity. In Figure 3 we additionally show that $L(t)$ is proportional to the skin thickness development where we use Zhang and Ni (2010) to compute $D$ for the range of water contents and take a mean of these values for use in $L$.

The diffusion-controlled collapse of a closed system foam is in stark contrast to the deformation (deformation refers to a change in the relative location of particles within the sample body) associated with an openly outgassing foam (Otsuki et al., 


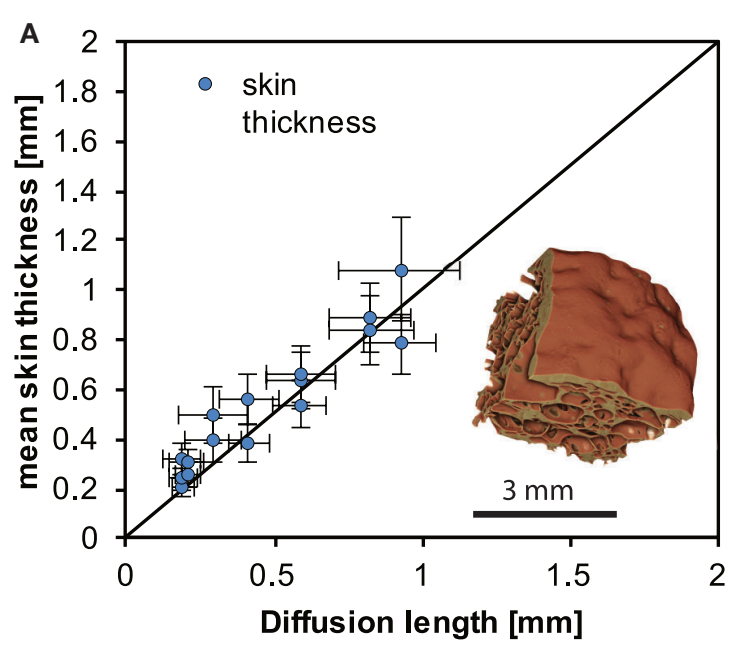

B

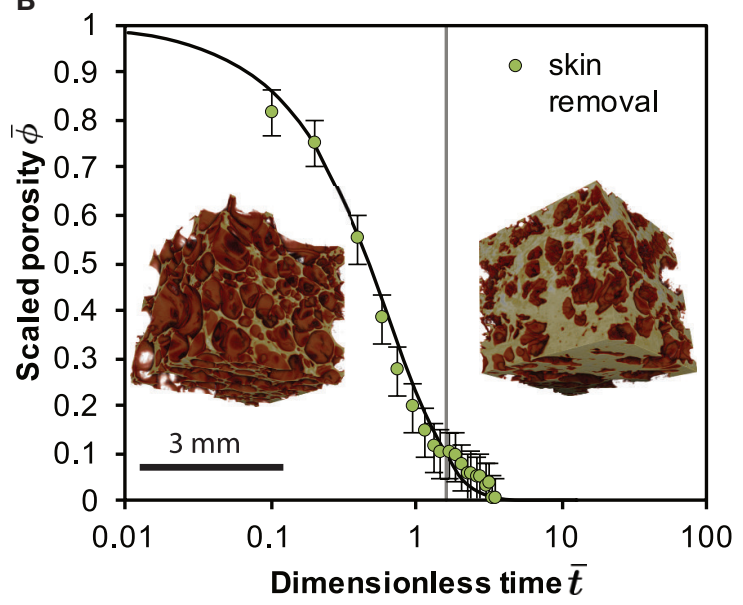

FIGURE 3 | (A) The scaling between skin thickness and the diffusion length of water $L$ for the case of the closed-foam outgassing. Here we use a mean of the diffusivity of water in the skin $\langle D\rangle$ in $L \approx \sqrt{D t}$. (B) The scaling between the volume deflation time and the capillary time for surface-tension driven densification of a permeable foam after Kennedy et al. (2016) for the open-foam outgassing case. The vertical gray line shows the first deviation from the model, suggesting the re-establishment of skin. Error bars refer to a minimum estimated error on the porosity of 0.05 . Insets show $X$-ray computed tomography reconstructions of the foams internal structure from Figure 1 developed with [BL-CT-A; in graph $A$ and $B$ (left)] and without an impermeable skin (BL-CT-B; right in graph $\mathrm{B}$ ) after a total of $48 \mathrm{~h}$ at high temperature.

2015; Kennedy et al., 2016). When the skin is removed from the sample, the system densifies. This is controlled by the shrinking of the bubble network that is at that point connected to the sample exterior where the pore phase can outgas. This proceeds under surface tension driven viscous flow at the pore-network interfaces and can be cast as the evolution of the sample porosity $\phi$ relative to the initial porosity $\phi_{i}$ and the scaling appropriate for the time-evolution of this process is using the capillary timescale $\lambda=a_{i} \mu / \Gamma$ where $a_{i}$ is the initial bubble radius, $\mu$ is the melt viscosity and $\Gamma$ is the surface tension (Taylor, 1934; Manga et al., 1998). The capillary time controls this process when surface tension is dominant over buoyancy forces, which is the case in our system. If the experimental time $t$ is taken from the point of skin removal $t_{0}$ then the dimensionless time is $\bar{t}=\left(t-t_{0}\right) / \lambda$ and then Wadsworth et al. (2016) provide a useful analytical approximation of a surface-tension-driven densification process, given by $\bar{\phi}=\exp (-3 \bar{t} / 2)$. Here $\bar{\phi}$ accounts for the final porosity $\phi_{f}$ that is non-zero, which was shown to be appropriate for collapsing pumice at high temperature (Kennedy et al., 2016) and is $\bar{\phi}=\left(\phi-\phi_{f}\right) /\left(\phi_{i}-\phi_{f}\right)$. This densification process will be operative until the permeability of the foam becomes low enough to impede outgassing as surface tension drives the bubble wall-motion, eventually leading to closure of the pore network completely. Using $\mu=1.58 \times 10^{8} \mathrm{~Pa}$ s (for $950^{\circ} \mathrm{C}$ and $0.1 \mathrm{wt} . \%$ water using Hess and Dingwell, 1996), $a_{i}=50 \mu \mathrm{m}$, from X-ray tomography of the foam interior, and $\Gamma=0.3 \mathrm{~N} \mathrm{~m}^{-1}$ (Gardner and Ketcham, 2011) we show that the open-system foam collapse process is well captured by this approximate model (Figure 3).

Once densification by this process is complete, the system transitions again from being open to closed. Once re-closed, the system can respond to potential changes in temperature and pressure that would permit re-growth of bubbles again. The resultant impermeable system can produce a thickening skin as described previously as diffusion of water from bubbles will continue. In our experiments a repetition of this process does not happen as the pore phase is replaced by air once the system is opened which is insoluble in the melt. Therefore, we can truly isolate the deflation mechanism from the diffusion mechanism. The magnitude of the volume decrease associated with surface-tension driven sample contraction is distinctly greater than the diffusion-driven outgassing and skin-maturation process (Figure 1). This highlights the fundamental control of impermeable skins in preventing permeable outgassing and that rupture of such thin skins can cause rapid deflation if the foam is internally permeable.

The formation of impermeable boundaries, in otherwise highly vesicular volcanic rocks, can be commonly observed on scales ranging from breadcrust bomb rims $\left(10^{-2} \sim 10^{-1} \mathrm{~m}\right.$; Wright et al., 2007) to contact between lava domes and dykes $\left(10^{-3} \sim 10^{0} \mathrm{~m}\right.$; (Schauroth et al., 2016). Self-sealing skin formation may additionally contribute to the development of impermeable structures inside a magmatic column. A key scenario in which rapid transitions occur between closed foam and open foam is fracturing in a conduit filled with bubbly magma (Gonnermann and Manga, 2003). However, the activity of water is likely to be different in the fracture and in the bubbles, which we suggest promotes skin formation at fracture margins. This could effectively localize permeability in the fracture networks and isolate them from the foamy regions adjacent, preventing further densification. At larger scales Castro et al. $(2012,2014)$ have established the central role of repeated open and closed diffusive mass transfer of water into fractures during the ascent of dense rhyolitic magma. Our model extends these observations to the more complex case where the fracturing occurs in magmatic foams, causing a shift from diffusion limited to permeability limited outgassing (and deflation), and back again to diffusion-limited outgassing as length scale modulated open system outgassing and deflation, followed by diffusion length scale modulated outgassing and deformation causing bubbles to shrink in the vicinity of the fracture. Our model shows 
that in the case of magmatic foams, diffusion-limited processes may be momentarily interrupted by more efficient permeabilitylimited outgassing steps. This is consistent with Castro et al. (2014) who have shown that the geochemical signature recorded in the volcanic glass contains evidence that the magmatic column undergoes both open and closed batched degassing. The different length scales that control skin formation and permeable outgassing lead to heterogeneous foams in volcanic environments and we stress that this has to be taken into account when interpreting outgassing trends and deformation at active volcanoes.

\section{CONCLUSIONS}

The experimental and analytical constraints on degassing and outgassing in magmatic foams from this study contribute to our understanding of permeability changes in volcanoes. We heated obsidian samples above their glass transition temperature, causing foaming and diffusion limited outgassing to the atmosphere. This caused an impermeable skin of dehydrated glass to form around the foamed samples, effectively sealing it from outgassing by gas flow through a permeable network of pores. When this impermeable skin is removed, the sample deflates rapidly during foam collapse which in our experiments is controlled by surface tension. Our models accurately predict the timescales of both skin formation and foam collapse. The results of our study imply that diffusional outgassing can cause local heterogeneities in magmatic foams that can disrupt permeable gas loss. This presents a possibility for repeated changes between closed and open system outgassing within the dynamic environment of a magmatic foam in a volcano.

\section{AUTHOR CONTRIBUTIONS}

FvA designed and ran experiments, conceptualized models, collected samples and analytical data (except $\mu \mathrm{CT}$ data), and wrote/edited the final manuscript. BK conceptualized models

\section{REFERENCES}

Ashwell, P. A., Kendrick, J. E., Lavallée, Y., Kennedy, B. M., Hess, K.-U., von Aulock, F. W., et al. (2015). Permeability of compacting porous lavas. J. Geophys. Res. 120, 1605-1622. doi: 10.1002/2014JB011519

Baker, D. R., Brun, F., O’Shaughnessy, C., Mancini, L., Fife, J. L., and Rivers, M. (2012). A four-dimensional X-ray tomographic microscopy study of bubble growth in basaltic foam. Nat. Commun. 3, 1135. doi: 10.1038/ncomms2134

Blower, J. (2001). Factors controlling permeability-porosity relationships in magma. Bull. Volcanol. 63, 497-504. doi: 10.1007/s004450100172

Blower, J. D., Mader, H. M., and Wilson, S. D. R. (2001). Coupling of viscous and diffusive controls on bubble growth during explosive volcanic eruptions. Earth Planet. Sci. Lett. 193, 47-56. doi: 10.1016/S0012-821X(01)00488-5

Cabrera, A., Weinberg, R. F., Wright, H. M. N., Zlotnik, S., and Cas, R. (2010). Melt fracturing and healing: a mechanism for degassing and origin of silicic obsidian. Geology 39, 67-70. doi: 10.1130/G31355.1

Castro, J. M., Bindeman, I. N., Tuffen, H., and Ian Schipper, C. (2014). Explosive origin of silicic lava: textural and $\delta \mathrm{D}-\mathrm{H}_{2} \mathrm{O}$ evidence for pyroclastic degassing during rhyolite effusion. Earth Planet. Sci. Lett. 405, 52-61. doi: 10.1016/j.epsl.2014.08.012 and experiment setup, collected analytical data and wrote/edited the final manuscript. AM conceptualized models, collected analytical data $(\mu \mathrm{CT})$, reconstructed and analyzed $\mu \mathrm{CT}$ data and wrote/edited the final manuscript. FW and YL conceptualized models and experiment setup, and wrote/edited the final manuscript. All authors have approved of the final version to be published and agreed to be accountable for all aspects of the work in ensuring that questions related to the accuracy or integrity of any part of the work are appropriately investigated and resolved.

\section{FUNDING}

Marsden Fast Start (09-UO-017C), New Zealand. European Research Council Starting Grant (306488; SLiM), and Advanced Grant (247076; EVOKES). NERC Standard Grant NE/M013561/1.

\section{ACKNOWLEDGMENTS}

This research was undertaken on the IRM and IMBL beamlines at the Australian Synchrotron, Victoria, Australia. We would like to thank the beamline scientists for their technical help. This work was supported by the Multi-modal Australian ScienceS Imaging and Visualisation Environment (MASSIVE) (www.massive.org.au). We would like to thank the reviewers for their constructive comments, and Kelly Russell for helpful discussions.

\section{SUPPLEMENTARY MATERIAL}

The Supplementary Material for this article can be found online at: http://journal.frontiersin.org/article/10.3389/feart. 2017.00046/full\#supplementary-material

Figure S1 | Backscattered electron image of a typical sample of Ben Lomond obsidian (BL-Pre) used in this study at 50, 100, 200, 400, and 800x magnification. All images were taken on a Philips XL 30 SEM at $20 \mathrm{kV}$.

Table S1 | List of analytical methods/experiments used on samples of this study.

Castro, J. M., Cordonnier, B., Tuffen, H., Tobin, M. J., Puskar, L., Martin, M. C., et al. (2012). The role of melt-fracture degassing in defusing explosive rhyolite eruptions at volcán Chaitén. Earth Planet. Sci. Lett. 333-334, 63-69. doi: 10.1016/j.epsl.2012.04.024

Dingwell, D. B. (1996). Volcanic dilemma : flow or blow? Science 273, 1054-1055. doi: 10.1126/science.273.5278.1054

Doube, M., Kłosowski, M. M., Arganda-Carreras, I., Cordelières, F. P., Dougherty, R. P., Jackson, J. S., et al. (2010). BoneJ: free and extensible bone image analysis in ImageJ. Bone 47, 1076-1079. doi: 10.1016/j.bone.2010. 08.023

Farquharson, J. I., Heap, M. J., Lavallée, Y., Varley, N. R., and Baud, P. (2016). Evidence for the development of permeability anisotropy in lava domes and volcanic conduits. J. Volcanol. Geother. Res. 323, 163-185. doi: 10.1016/j.jvolgeores.2016.05.007

Gardner, J. E., and Ketcham, R. A. (2011). Bubble nucleation in rhyolite and dacite melts: temperature dependence of surface tension. Contrib. Mineral. Petrol. 162, 929-943. doi: 10.1007/s00410-011-0632-5

Gonnermann, H. M., and Manga, M. (2003). Explosive volcanism may not be an inevitable consequence of magma fragmentation. Nature 426, 432-435. doi: $10.1038 /$ nature02138 
Gonnermann, H. M., and Manga, M. (2007). The fluid mechanics inside a volcano. Аnпu. Rev. Fluid Mech. 39, 321-356. doi: 10.1146/annurev.fluid.39.050905.110207

Ihinger, P. D., Hervig, R. L., McMillan, P. F., Zhang, Y., and Stolper, E. M. (1994). Analytical methods for volatiles in glasses. Rev. Mineral. Geochem. 30, 67-121.

Kendrick, J. E., Lavallée, Y., Hess, K., Heap, M. J., Gaunt, H. E., Meredith, P. G., et al. (2013). Tracking the permeable porous network during strain-dependent magmatic flow. J. Volcanol. Geother. Res. 260, 117-126. doi: 10.1016/j.jvolgeores.2013.05.012

Kennedy, B. M., Wadsworth, F. B., Vasseur, J., Ian Schipper, C., Mark Jellinek, A., von Aulock, F. W., et al. (2016). Surface tension driven processes densify and retain permeability in magma and lava. Earth Planet. Sci. Lett. 433, 116-124. doi: 10.1016/j.epsl.2015.10.031

Lindoo, A., Larsen, J. F., Cashman, K. V., Dunn, A. L., and Neill, O. K. (2016). An experimental study of permeability development as a function of crystal-free melt viscosity. Earth Planet. Sci. Lett. 435, 45-54. doi: 10.1016/j.epsl.2015.11.035

Liu, Y., Zhang, Y., and Behrens, H. (2005). Solubility of $\mathrm{H}_{2} \mathrm{O}$ in rhyolitic melts at low pressures and a new empirical model for mixed $\mathrm{H}_{2} \mathrm{O}-\mathrm{CO}_{2}$ solubility in rhyolitic melts. J. Volcanol. Geother. Res. 143, 219-235.

Llewellin, E. W., Mader, H. M., and Wilson, S. D. R. (2002). The rheology of a bubbly liquid. Proc. R. Soc. A Math. Phys. Eng. Sci. 458, 987-1016. doi: 10.1098/rspa.2001.0924

Manga, M., Castro, J., Cashman, K. V., and Loewenberg, M. (1998). Rheology of bubble-bearing magmas. J. Volcanol. Geother. Res. 87, 15-28. doi: 10.1016/s0377-0273(98)00091-2

Martel, C., Dingwell, D. B., Spieler, O., Pichavant, M., and Wilke, M. (2000). Fragmentation of foamed silicic melts: an experimental study. Earth Planet. Sci. Lett. 178, 47-58. doi: 10.1016/S0012-821X(00)00062-5

McIntosh, I. M., Llewellin, E. W., Humphreys, M. C. S., Nichols, A. R. L., Burgisser, A., Schipper, C. I., et al. (2014). Distribution of dissolved water in magmatic glass records growth and resorption of bubbles. Earth Planet. Sci. Lett. 401, 1-11. doi: 10.1016/j.epsl.2014.05.037

Michaut, C., Bercovici, D., and Sparks, R. S. J. (2009). Ascent and compaction of gas rich magma and the effects of hysteretic permeability. Earth Planet. Sci. Lett. 282, 258-267. doi: 10.1016/j.epsl.2009.03.026

Navon, O., Chekhmir, A., and Lyakhovsky, V. (1998). Bubble growth in highly viscous melts: theory, experiments, and autoexplosivity of dome lavas. Earth Planet. Sci. Lett. 160, 763-776. doi: 10.1016/S0012-821X(98)00126-5

Navon, O., and Lyakhovsky, V. (1998). Vesiculation processes in silicic magmas. Geol. Soc. Lond. Spec. Publ. 145, 27-50. doi: 10.1144/GSL.SP.1996.145.01.03

Okumura, S., Nakamura, M., Takeuchi, S., and Tsuchiyama, A. (2009). Magma deformation may include non-explosive volcanism via degassing through bubble networks. Earth Planet. Sci. Lett. 281, 267-274. doi: 10.1016/j.epsl.2009.02.036

Okumura, S., Nakamura, M., Tsuchiyama, A., Nakano, T., and Uesugi, K. (2008). Evolution of bubble microstructure in sheared rhyolite: formation of a channellike bubble network. J. Geophys. Res. 113, 18. doi: 10.1029/2007JB005362

Otsuki, S., Nakamura, M., Okumura, S., and Sasaki, O. (2015). Interfacial tensiondriven relaxation of magma foam: an experimental study. J. Geophys. Res. 120, 7403-7424. doi: 10.1002/2015JB012391

Pistone, M., Caricchi, L., Fife, J. L., Mader, K., and Ulmer, P. (2015). In situ X-ray tomographic microscopy observations of vesiculation of bubble-free and bubble-bearing magmas. Bull. Volcanol. 77, 1-15. doi: 10.1007/s00445-015-0992-1

Proussevitch, A. A., Sahagian, D., and Anderson, A. T. (1993). Dynamics of diffusive bubble growth in magmas: isothermal case. J. Geophys. 98, 22283-22307. doi: 10.1029/93jb02027

Rust, A. C., and Cashman, K. V. (2011). Permeability controls on expansion and size distributions of pyroclasts. J. Geophys. Res. 116:B11202. doi: 10.1029/2011jb008494
Ryan, A. G., Russell, J. K., Nichols, A. R. L., Hess, K.-U., and Porritt, L. A. (2015). Experiments and models on $\mathrm{H}_{2} \mathrm{O}$ retrograde solubility in volcanic systems. Am. Mineral. 100, 774-786. doi: 10.2138/am-2015-5030

Schauroth, J., Wadsworth, F. B., Kennedy, B., von Aulock, F. W., Lavallée, Y., Damby, D. E., et al. (2016). Conduit margin heating and deformation during the AD 1886 basaltic Plinian eruption at Tarawera volcano, New Zealand. Bull. Volcanol. 78, 12. doi: 10.1007/s00445-016-1006-7

Schneider, C. A., Rasband, W. S., and Eliceiri, K. W. (2012). NIH Image to ImageJ: 25 years of image analysis. Nat. Methods 9, 671-675. doi: 10.1038/nmet h.2089

Sparks, R. S. J. (1978). The dynamics of bubble formation and growth in magmas: a review and analysis. J. Volcanol. Geother. Res. 3, 1-37. doi: 10.1016/0377-0273(78)90002-1

Stasiuk, M. V., Barclay, J., Carroll, M. R., Jaupart, C., Ratté, J. C., Sparks, R. S. J., et al. (1996). Degassing during magma ascent in the Mule Creek vent (USA). Bull. Volcanol. 58, 117-130. doi: 10.1007/s004450050130

Stevenson, R. J., Briggs, R. M., and Hodder, A. P. W. (1993). Emplacement history of a low-viscosity, fountain-fed pantelleritic lava flow. J. Volcanol. Geother. Res. 57, 39-56. doi: 10.1016/0377-0273(93)90030-U

Stevenson, R. J., Dingwell, D. B., Bagdassarov, N., and Manley, C. (2001). Measurement and implication of "effective" viscosity for rhyolite flow emplacement. Bull. Volcanol. 63, 227-237. doi: 10.1007/s0044501 00137

Taylor, G. I. (1934). The Formation of Emulsions in Definable Fields of Flow. Proc. R. Soc. Lond. A 146, 501-523. doi: 10.1098/rspa.1934.0169

Tuffen, H., Dingwell, D. B., and Pinkerton, H. (2003). Repeated fracture and healing of silicic magma generate flow banding and earthquakes. Geology 31, 1089-1092. doi: 10.1130/G19777.1

von Aulock, F. W. (2013). Bubbles, Crystals and Cracks in Cooling Magma. Christchurch: University of Canterbury.

von Aulock, F. W., Kennedy, B. M., Schipper, C. I., Castro, J. M., Martin, D., Oze James, C., et al. (2014). Advances in Fourier transform infrared spectroscopy of natural glasses: from sample preparation to data analysis. Lithos 206-207, 52-64. doi: 10.1016/j.lithos.2014.07.017

Wadsworth, F. B., Vasseur, J., Llewellin, E. W., Schauroth, J., Dobson, K. J., Scheu, B., et al. (2016). Sintering of viscous droplets under surface tension. Proc. R. Soc. A 472:20150780. doi: 10.1098/rspa.2015.0780

Wright, H. M. N., Cashman, K., Rosi, M., and Cioni, R. (2007). Breadcrust bombs as indicators of Vulcanian eruption dynamics at Guagua Pichincha volcano, Ecuador. Bull. Volcanol. 69, 281-300. doi: 10.1007/s00445-006-0073-6

Yoshimura, S., and Nakamura, M. (2008). Diffusive dehydration and bubble resorption during open-system degassing of rhyolitic melts. J. Volcanol. Geother. Res. 178, 78-87. doi: 10.1016/j.jvolgeores.2008.01.017

Zhang, Y. (1999). $\mathrm{H}_{2} \mathrm{O}$ in Rhyolitic glasses and melts: measurement, speciation, solubility, and diffusion. Rev. Geophys. Space Phys. 37, 493-516. doi: 10.1029/1999RG900012

Zhang, Y., and Ni, H. (2010). Diffusion of H, C, and O components in silicate melts. Rev. Mineral. Geochemistry 72, 171-225. doi: 10.2138/rmg.2010.72.5

Conflict of Interest Statement: The authors declare that the research was conducted in the absence of any commercial or financial relationships that could be construed as a potential conflict of interest.

Copyright (c) 2017 von Aulock, Kennedy, Maksimenko, Wadsworth and Lavallée. This is an open-access article distributed under the terms of the Creative Commons Attribution License (CC BY). The use, distribution or reproduction in other forums is permitted, provided the original author(s) or licensor are credited and that the original publication in this journal is cited, in accordance with accepted academic practice. No use, distribution or reproduction is permitted which does not comply with these terms. 